\title{
Pelatihan dan Pendampingan Penulisan Buku Ajar Bagi Dosen Pemula Melalui Whatsapp Group
}

\author{
Pahriah*, Baiq Rina Amalia Safitri \\ Universitas Pendidikan Mandalika, Jl. Pemuda No. 59 A, Mataram, 83125 Indonesia \\ Email Korespondensi: pahriah@ikipmataram.ac.id
}

Diterima: Mei 2020; Revisi: Mei 2020; Diterbitkan: Mei 2020

\begin{abstract}
Abstrak
Terbatasnya kemampuan guru dan dosen dalam menghasilkan karya tulis ilmiah berupa buku ajar dan karya tulis lainnya disinyalir menjadi kendala pembangunan sistem pendidikan yang baik di Indonesia. Pengabdian masyarakat ini bertujuan untuk memberikan pemahaman dan pengalaman bagi dosen pemula terkait penyusunan buku ajar dari Rencana Pembelajaran Semester (RPS) matakuliah yang diampu dan mengahasilkan buku ajar yang dapat digunakan di kampus masing-masing. Subjek dalam pengabdian ini adalah dosen pemula dari berbagai perguruan tinggi yang ada di Indonesia yang berjumlah 956 orang yang terbagi menjadi empat group WhatsApp. Kegiatan pengabdian ini dilaksanakan dengan metode ceramah, diskusi, dan praktik. Tanggapan peserta yang mengikuti pelatihan penulisan buku ajar diperoleh dari testimoni peserta. Hasil testimoni peserta menunjukkan bahwa group menulis buku ajar yang diikuti sangat bermanfaat dalam meningkatkan pemahaman peserta dan sangat membantu dalam proses penyusunan buku ajar bagi masing-masing peserta.
\end{abstract}

Kata Kunci: pelatihan; pendampingan; buku ajar; whatsapp group

\section{Training and Assistance in Writing Textbooks for Novice Lecturers through Whatsapp Group}

\begin{abstract}
The limited ability of teachers and lecturers to produce scientific papers in the form of textbooks and other written works is allegedly an obstacle to the development of a good education system in Indonesia. This community service aimed to provide understanding and experience for novice lecturers related to the preparation of textbooks from the Semester Learning Plan (RPS) for taught courses and produce textbooks that can be used on their respective campuses. The subjects in this service are novice lecturers from various universities in Indonesia, totaling 956 people who are divided into four WhatsApp groups. This service activity is carried out using lecture, discussion, and practice methods. The responses of participants who took part in the textbook writing training were obtained from participant testimonials. The results of participant testimonials show that the group writing textbooks that are followed is very useful in increasing participants' understanding and is very helpful in the process of compiling textbooks for each participant.
\end{abstract}

Keywords: training; assisting; textbooks; whatsapp group

How to Cite: Pahriah, P., \& Safitri, B. (2020). Pelatihan dan Pendampingan Penulisan Buku Ajar Bagi Dosen Pemula Melalui Whatsapp Group. Lumbung Inovasi: Jurnal Pengabdian kepada Masyarakat, 5(1), 9-15. doi:https://doi.org/10.36312/linov.v5i1.459

https://doi.org/10.36312/linov.v5i1.459

Copyright@ 2020, Pahriah \& Safitri This is an open-access article under the CC-BY License.

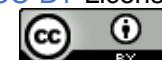

\section{PENDAHULUAN}

Proses pengembangan potensi manusia sepanjang hayat dimulai dari pendidikan. Salah satu unsur konkrit yang sangat penting dalam upaya peningkatan kualitas sumber daya manusia adalah peningkatan mutu pendidikan (Badri \& Riasti, 2013). Salah satu unsur penyelenggaraan pendidikan tinggi adalah dosen. Dosen merupakan tenaga akademik yang bertugas merencanakan dan melaksanakan proses pembelajaran. Proses pembelajaran di 
kelas akan sukses jika dosen memiliki keseriusan dalam mengatur proses pembelajaran agar tujuan dapat tercapai seperti yang tertuang dalam Undang-Undang Nomor 14 tahun 2005 tentang Guru dan Dosen menyebutkan peran dan tugas pokok dosen telah berkembang dari yang semula lebih ditekankan pada tugas mengajar menjadi pendidik profesional dan ilmuwan dengan tugas utama mentransformasikan, mengembangkan, dan menyebarkan ilmu pengetahuan, teknologi, dan seni melalui pendidikan/pengajaran, penelitian dan pengabdian kepada masyarakat (Departemen Pendidikan Nasional, 2005).

Tugas utama dosen dalam melaksanakan Tridharma Perguruan Tinggi merupakan satu kesatuan dharma atau kegiatan, karena ketiga dharma tersebut hanya dapat dibedakan tetapi tidak dapat dipisahkan, karena saling terkait dan mendukung satu sama lain. Dharma pendidikan dan pengajaran akan menghasilkan problematika dan konsep-konsep yang dapat menggerakkan penelitian untuk menghasilkan publikasi ilmiah, sebaliknya dari penelitian dan publikasi ilmiah akan memperkaya dan memperbaharui khasanah ilmu untuk digunakan dalam pendidikan dan pengajaran (Ristekdikti, 2019).

Salah satu bahan rujukan yang digunakan dosen saat mengajar adalah buku ajar.Pada Pedoman Operasional Penilaian Angka Kredit (POPAK) kenaikan jabatan akademik dosen, dosen dituntut untuk membuat buku ajar/buku teks. Batas maksimal yang diakui untuk kegiatan mengembangkan bahan pengajaran seperti buku ajar/buku teks yakni 1 buku/tahun.

Buku ajar adalah seperangkat materi substansi pelajaran yang disusun secara sistematis menampilkan keutuhan dari kompetensi yang akan dikuasai oleh peserta didik dalam kegiatan pembelajaran (Millah et al., 2012). Dimana tujuan dari buku ajar tidak lain membantu komunikasi antara pengajar dan peserta didik, dengan adanya buku ajar maka pembelajaran lebih efektif karena dosen lebih banyak waktu untuk membimbing mahasiswanya dalam memahami suatu topik pembelajaran.

Namun pada kenyataannya, belum banyak dosen yang sadar akan pentingnya buku ajar ini. Hal ini dapat dilihat dari ketercapaian Indonesia yang masih kalah dengan Negara Singapura, Malaysia, dan Thailand yang mendapat predikat sebagai Negara dengan sistem pendidikan terbaik se-ASEAN pada tahun 2015 versi Economic Cooperation and Development's (OECD) (Elisa \& Intan, 2019) yang melakukan survey terkait literasi membaca, matematika, dan sains.

Menurut Budiana, et al (2018), kendala terbesar yang sedang dihadapi guru atau dosen adalah kemampuan masih terbatas dalam menghasilkan karya tulis ilmiah yang berupa buku ajar dan karya tulis lainnya yang disusun oleh guru atau dosen. Hal ini sejalan dengan Sopiah, et al (2019) menyatakan bahwa konsumen terbanyak dari buku ajar adalah guru atau dosen yang dibeli dari took-toko buku, mereka belum berusaha untuk menyusun buku ajar sendiri untuk kepentingan mengajar maupun kenaikan jabatan fungsional. Padahal, buku ajar yang disusun oleh guru atau dosen untuk keperluan anak didiknya sendiri dan tentu kepentingan guru atau dosen sendiri.

Salah satu upaya yang diharapkan mampu mengatasi permasalahan tersebut adalah dengan cara melaksanakan pelatihan dan pendampingan dalam penulisan buku ajar. Untuk dapat menjangkau seluruh wilayah Indonesia, maka pelatihan dan pendampingan menggunakan daring (online). Salah satu yang dapat mendukung pelatihan online adalah whatsapp. Menurut Wikipedia (2020), WhatsApp Messenger adalah aplikasi pesan untuk ponsel cerdas. WhatsApp Messenger merupakan aplikasi pesan lintas platform yang memungkinkan kita bertukar pesan tanpa pulsa, karena WhatsApp Messenger menggunakan paket data internet. Aplikasi WhatsApp Messenger menggunakan koneksi internet 3G, 4G atau WiFi untuk komunikasi data. Dengan menggunakan WhatsApp, kita dapat melakukan obrolan daring, berbagi file, bertukar foto dan lain-lain.

Berdasarkan permasalahan di atas maka dipandang perlu diadakan Pelatihan dan Pendampingan Penyusunan Buku Ajar Bagi Dosen Indonesia melalui WhatsAap Group.Kegiatan ini dilakukan dalam rangka membentuk kebiasaan dosen untuk menulis/menyusun buku ajarsendiri untuk kepentingan anakdidiknya sendiri dan atau bahkan untuk dipublikasikan secara lokal, regional maupun nasional. Dengan keterampilan ini, diharapkan dosen dapat melaksanakan tugas utamanya dengan lebih baik lagi.

Tujuan dari kegiatan pelatihan dan pendampingan penulisan buku ajar ini adalah pertama untuk memberikan pemahaman dan pengalaman bagi dosen pemula tentang 
bagaimana menyusunan buku ajar dari pengembangan Rencana Pembelajaran Semester (RPS) matakuliah yang diampunya, kedua untuk mengahasilkan buku ajar yang dapat digunakan dan diterapkan di kampus masing-masing serta dapat pula digunakan oleh dosendosen lainnya dengan matakuliah yang sama.

\section{METODE PELAKSANAAN}

Metode yang digunakan dalam kegiatan pengabdian kepada masyarakat ini adalah ceramah, diskusi, bimbingan dan praktik. Materi yang diberikan adalah teknik penyusunan buku ajar; strategi jitu menulis buku monograf; dan cerdas menulis buku referensi.Metode ceramah digunakanbertujuan menghendaki peserta harus mendapat informasi yang sama dalam jumlah peserta yang banyak. Kegiatan pembelajaran yang menekankan pada penyampaian informasi secara verbal dan cenderung searah (pengajar kepada peserta) ini dapat terstruktur, menggunakan teknologi rendah, dan memungkinkan, kegiatan ini untuk mengajarkan para peserta dalam waktu relatif singkat (Amri, 2013).

Pada tiap materi yang disampaikan, peserta dapat berdialog dan berdiskusi dengan tim pengabdian bagaimana teknik menyusun buku ajar yang baik mulai dari penentuan topik/bidang ilmu buku ajar yang akan dibuat, bagian isi buku ajar dan penutup serta bagaimana mengindari plagiat dalam penyusunan buku ajar. Tujuan digunakan metode diskuisi supaya peserta memperoleh kesamaan pandang tentang sesuatu masalah yang dirasakan bersama (Samani \& Hariyanto, 2013). Menurut Ermi (2015), diskusi merupakan suatu metode pembelajaran yang di dalamnya terdapat percakapan antara individu dengan indvidu lainnya yang terbentuk ke dalam wadah atau kelompok yang dihadapkan oleh suatu permasalahan sehingga mereka dapat bertukar pikiran untuk mendapatkan pemecahan masalah yang benar melalui kesepakatan bersama.

Peserta diminta untuk membuat buku ajar sesuai konteks yang telah ditentukan dengan cara mencari teman sebidang dalam group WhatsApp sehingga terbentuk group-group kecil sesuai dengan bidang masing-masing.

Prosedur kegiatan pengabdian kepada masyarakat ini dilaksanakan dalam beberapa tahap, yaitu perencanaan, pelaksanaan, pelatihan, dan evaluasi yang dijelaskan secara singkat sebagai berikut.

\section{Tahap perencanaan}

Pada tahap perencanaan, tim pengabdi merekrut peserta melalui goup facebook yaitu Dosen Menulis dan Ikatan Dosen Republik Indonesia (IDRI) dengan menempatkan link WhatsApp pada halaman facebook.

\section{Tahap pelaksanaan}

Tahap pelaksanaan kegiatan terdiri dari pemberian materi mengenai teknik penyusunan buku ajar, strategi jitu menulis buku monograf, cerdas menulis buku referensi, dan cara menghindari plagiat dalam penyusunan buku ajar.

\section{Tahap pelatihan}

Tahap ini dilakukan dengan praktik, tim pengabdian meminta membuat buku ajar dari RPS Mata kuliah masing-masing dosen, praktik pembuatan buku ajar dilakukan secara mandiri maupun secara kolaboratif dengan teman-teman sebidang dalam group.

\section{Tahap evaluasi}

Evaluasi pelatihan dilakukan untuk mengetahui pencapaian tujuan pelaksanaan pelatihan (Rizka et al., 2016). Pada tahap terakhir tim pengabdi merekap testimoni dari para peserta pelatihan.

\section{HASIL DAN PEMBAHASAN}

Pelatihan dan pendampingan penulisan buku ajar bagi dosen pemula melalui WA grouptelah dilaksanakan pada tanggal 12 Juni 2020 sampai pada tanggal 12 September 2020. Peserta pelatihan adalah dosen dari berbagai kampus di seluruh Indonesia sebanyak 956 orang yang terdistribusi menjadi empat group WA. 


\section{Tahap Perencanaan}

Tahap perencanaan pada kegiatan pengabdian masyarakat ini berjalan dengan lancar. Pendataan/perekrutan peserta menulis buku ajar dilakukan melalui goup facebook yaitu Dosen Menulis dan Ikatan Dosen Republik Indonesia (IDRI) dengan menempatkan link WhatsApp pada halaman facebook seperti pada Gambar 1. Dari dua group facebook tersebut terbentuk empat group WhatsApp buku ajar yaitu: Group Menulis Buku Ajar\#1 dengan jumlah peserta 236 orang, Group Menulis Buku Ajar\#2 dengan jumlah peserta 249 orang, Group Menulis Buku Ajar\#3 dengan jumlah peserta 252 orang,dan Group Menulis Buku Ajar\#4 dengan jumlah peserta 219 orang (Gambar 2) sehingga total peserta 956 orang.

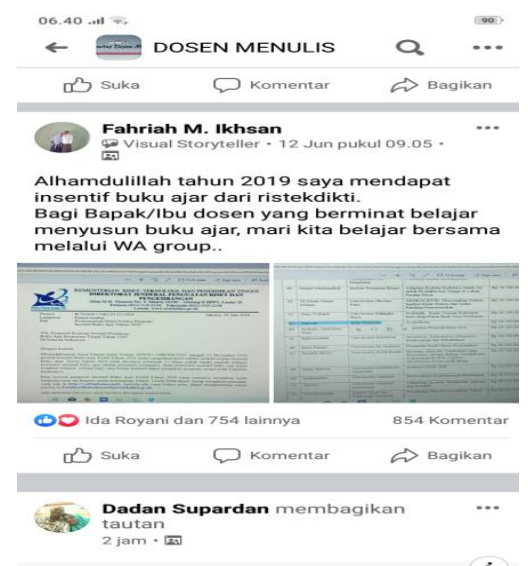

(a)

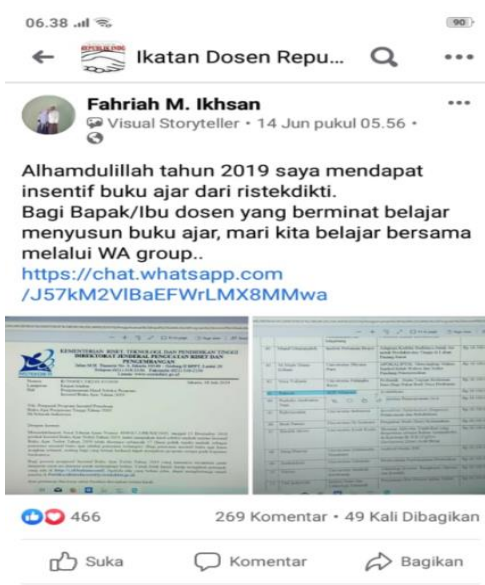

(b)

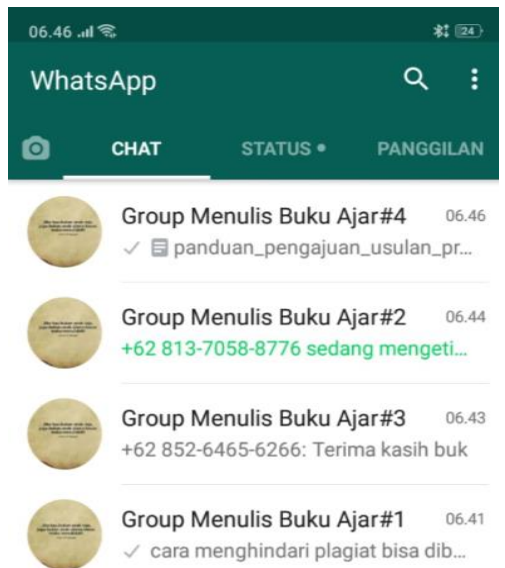

(c)

Gambar 1. (a) Perekrutan peserta melalui group facebook Dosen Menulis, (b) Perekrutan peserta melalui group facebook Ikatan Dosen Republik Indonesia (IDRI), (c) Terbentuk empat group WhatsApp buku ajar.

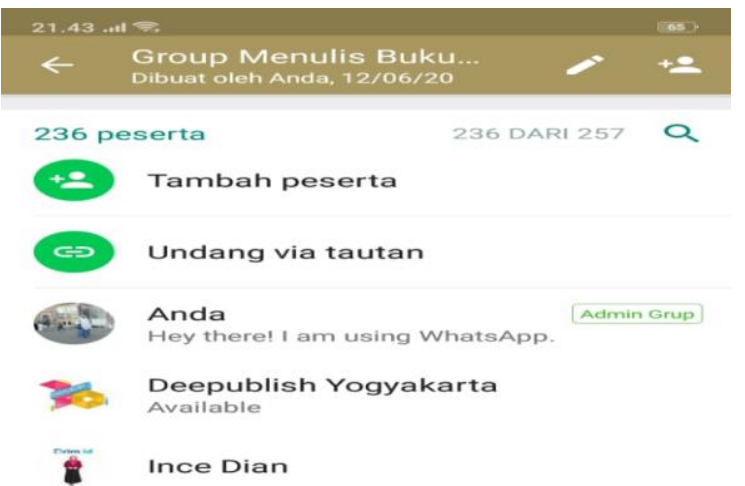

(a)

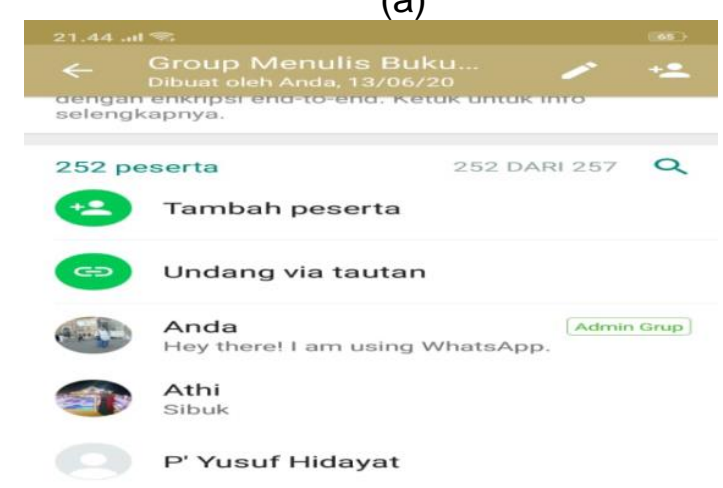

(c)

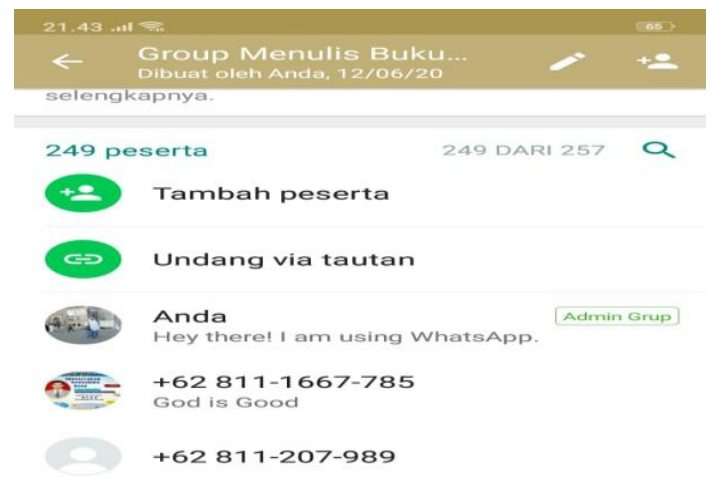

(b)

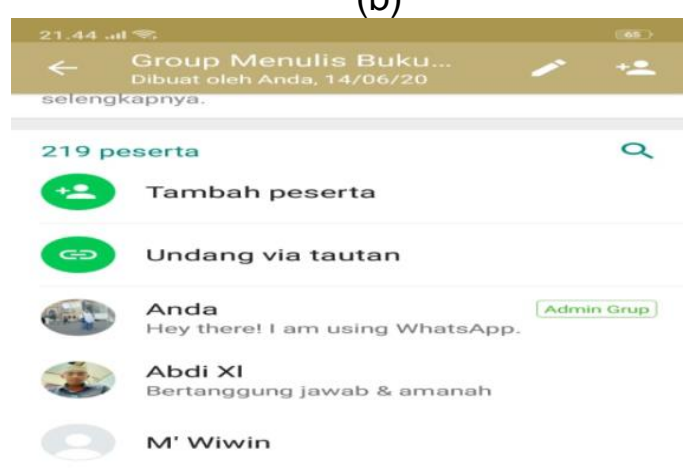

(d)

Gambar 2. (a) Group Menulis Buku Ajar\#1, (b) Group Menulis Buku Ajar\#2 Group Menulis Buku Ajar\#3, (c) Group Menulis Buku Ajar\#4. 


\section{Tahap Pelaksanaan}

Pada tahap ini kegiatan dimulai dengan pemberian materi oleh tim pengabdian yaitu antara lain: teknik penyusunan buku ajar, strategi jitu menulis buku monograf, cerdas menulis buku referensi, dan cara menghindari plagiat dalam penyusunan buku ajar.Materi ini penting diketahui oleh peserta agar peserta memahami baik bagaimana membedakan antara buku ajar, buku monograf, dan buku referensi. Melalui pemaparan dengan sistem sharing dan diskusi, banyak sekali pertanyaan-pertanyaan yang diajukan peserta. Ada peserta yang bertanya mengenai contoh buku ajar, monograf, dan referensi yang sudah dibuat tim pengabdi, cara agar buku ajar yang dibuat layak untuk diterbitkan. Dari kegiatan sharing dan diskusi ini, terlihat antusiasme peserta berdasarkan interaksi peserta dengan pemateri sangat baik.

\section{Tahap Pelatihan}

Pada kegiatan pelatihan ini, tim pengabdi meminta setiap peserta membuat buku ajar dari RPS matakuliah masing-masing dosen, praktik pembuatan buku ajar dilakukan secara mandiri maupun secara kolaboratif dengan teman-teman sebidang dalam group sehingga terbentuk 10 group kecildalam penyusunan buku ajar secara kolaboratif diantaranya: (1) buku ajar kewirausahaan, (2) buku ajar Matematika, (3) buku ajar kebidanan, (5) buku ajar kesehatan masyarakat, (6) buku ajar aljabar, (7) buku ajar PGSD, (8) buku ajar bidang kesehatan, (9) buku ajar bahasa inggris, (10) buku ajar telaah kurikulum (Gambar 3).

Pada sesi ini, banyak dilakukan sharing antara peserta dengan peserta sebidang, mereka mulai menyusun buku ajar dari RPS yang sudah disepakati bersama, satu orang memperoleh satu atau dua materi/bab tergantung jumlah penulis, semakin banyak jumlah penulis semakin sedikit materi yang akan ditulis. Monitoring dan evaluasi dalam kelompok kecil ini dilakukan satu mingggu setelah pembagian materi.
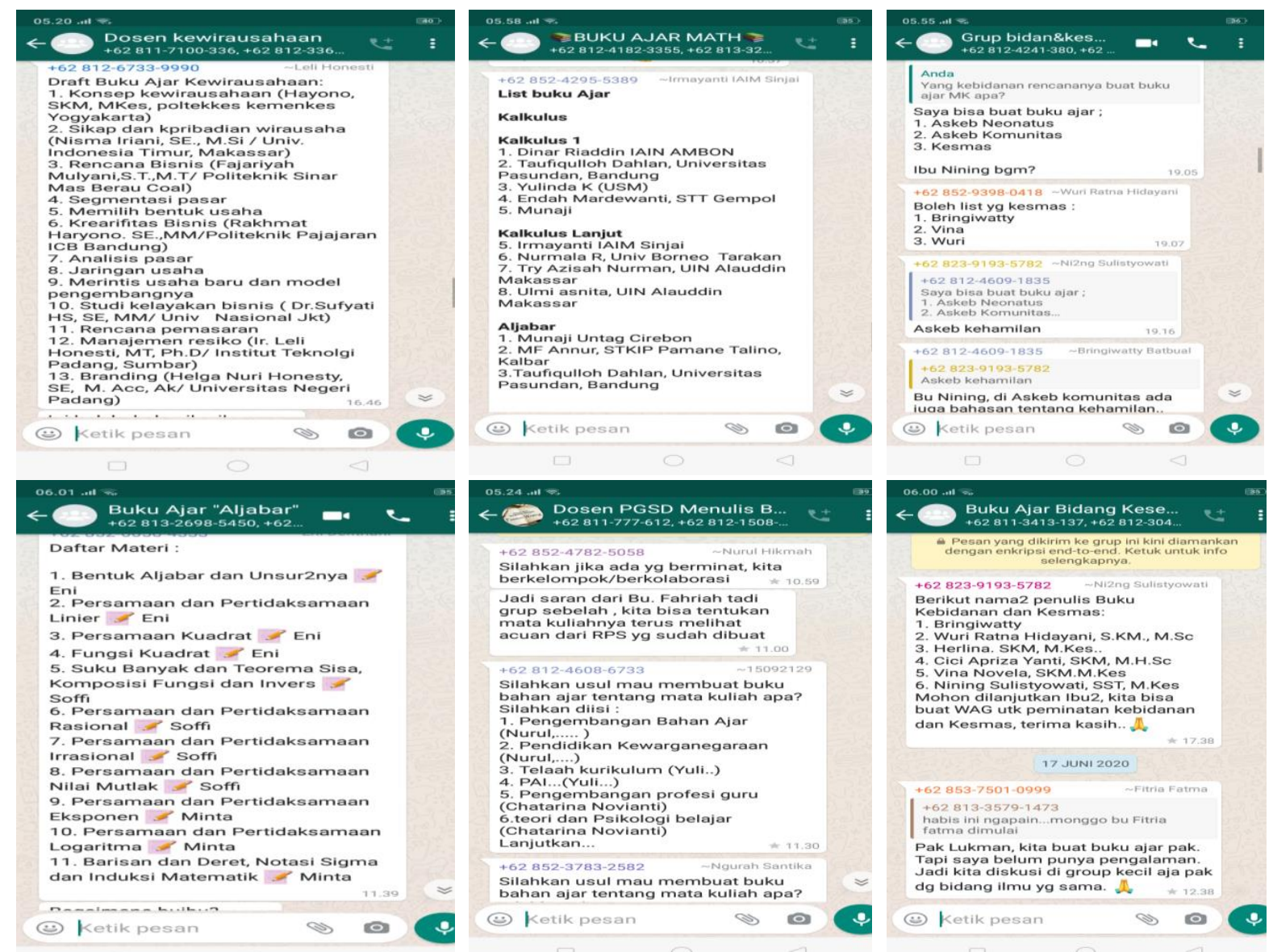

Gambar 3. Penulisan buku ajar secara kolaborasi 


\section{Tahap Evaluasi}

Pada tahap terakhir tim pengabdi merekap testimoni dari para peserta pelatihan. selama pelatihan berlangsung, para peserta sangat aktif dan semangat serta antusias, dilihat dari tanggapan para peserta yang disampaikan melalui whataapp, antara lain dapat dilihat pada beberapa testimoni yang disampaikan para peserta pada Gambar 4 di bawah ini.

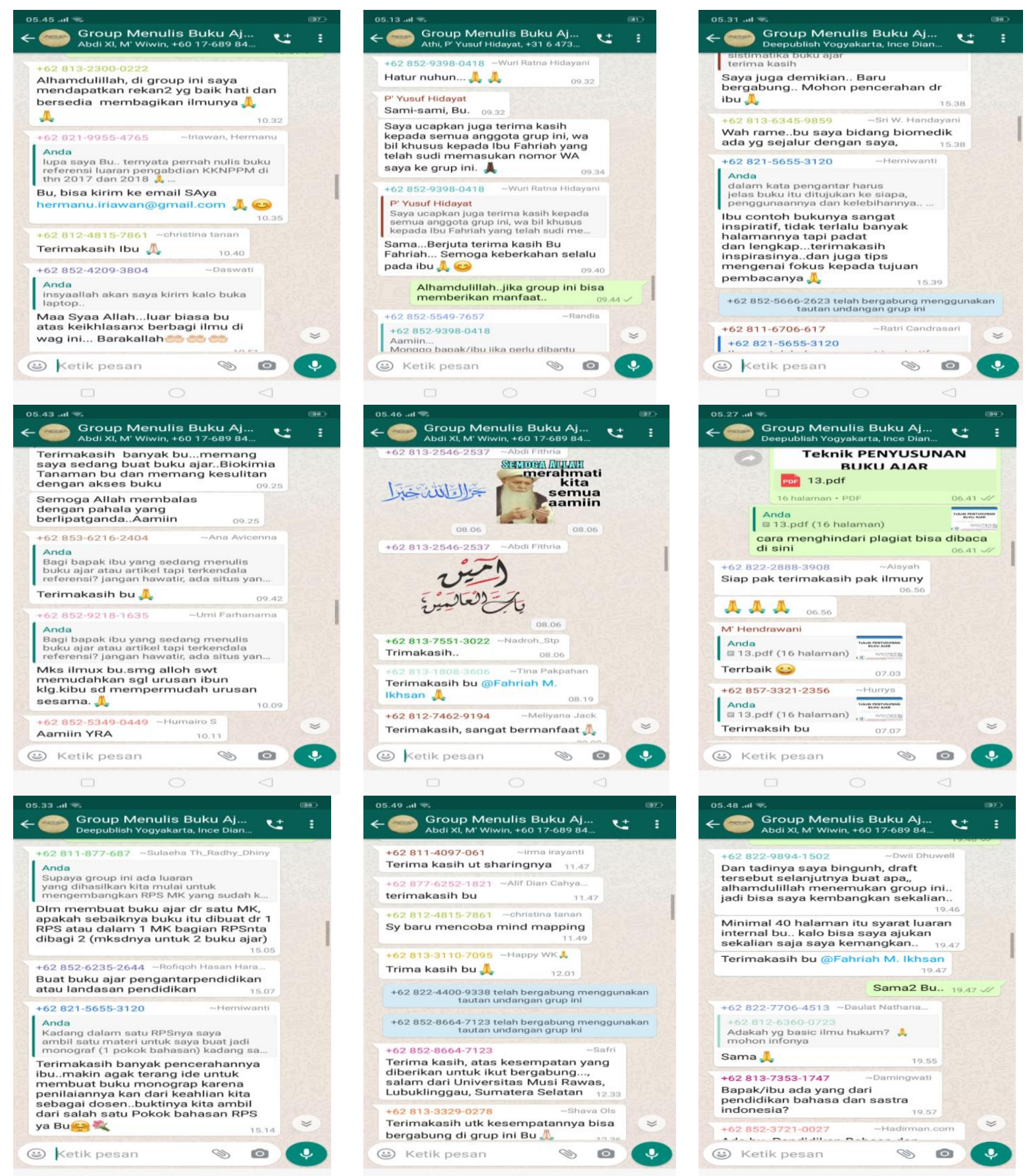

Gambar 4. Testimoni dari kebermanfaatan group whatsapp menulis buku ajar

Berdasarkan hasil kegiatan yang telah dilakukan, subjek pengabdian ini merasa sangat terbantu secara signifikan setelah mengikuti kegiatan pengabdian ini. Hasil serupa juga disampaikan oleh Haerazi et al (2020) yang melakukan pelatihan penulisan karya tulis ilmiah bagi guru se-Lombok Tengah yang menemukan bahwa peserta pelatihan aktif dan responsive selama kegiatan. Namun meski-begitu kegiatan tersebut dilakukan pada guru sekolah menengah dalam menulis/menyusun artikel penelitian. 


\section{KESIMPULAN}

Setelah kegiatan pengabdian masyarakat dilakukan, peserta mendapatkan pemahaman dan pengalaman dalam pembuatan buku ajar baik secara mandari maupun secara kolaborasi dari teman-teman sebidang dalam group. Kegiatan ini menghasilkan beberapa produk buku ajar diantaranya: buku ajar Matematika, buku ajar kebidanan, buku ajar kesehatan masyarakat, buku ajar aljabar, buku ajar PGSD, buku ajar bidang kesehatan, buku ajar bahasa inggris, buku ajar telaah kurikulum sehingga kemudian dapat diterbitkan. Indikator keberhasilan kegiatan pelatihan ini juga tampak dari hasil respon atau testimoni peserta mengenai kebermanfaatan kegiatan pelatihan yang diikuti dengan rata-rata menyatakan group menulis buku ajar yang diikuti sangat bermanfaat.

\section{REKOMENDASI}

Perlu diadakan kegiatan lanjutan terkait pelatihan penyusunan perangkat-perangkat pendukung lainnya seperti scenario pembelajaran dan instrumen pembelajaran. Hasil kegiatan ini juga dapat menjadi rujukan untuk melakukan pelatihan penyusunan buku ajar perkuliahan yang belum terakomodasi dalam kegiatan ini di masa mendatang.

\section{DAFTAR PUSTAKA}

Amri, S. (2013). Pengembangan \& modal pembelajaran dalam kurikulum 2013. Prestasi Pustaka.

Badri, N., \& Riasti, B. K. (2013). Pembuatan Media Pembelajaran Interaktif Pada SMK Negeri Tiga Jepara Dengan Materi Power Point 2007. Speed - Sentra Penelitian Engineering Dan Edukasi, 4(1), 73-78. https://doi.org/10.3112/speed.v4i1.948

Budiana, K. M. M., Djuwari, D., Joicenda, J., Irwandi, S. A., \& Muntaha, M. (2018). Pelatihan Penulisan Karya Tulis IImiah Populer Bagi Guru-Guru SMA/SMK/MA Se-Surabaya, Gresik dan Sidoarjo di STIE Perbanas Surabaya. Seminar Nasional Hasil Pengabdian Kepada Masyarakat, 2(1), 299-304.

Departemen Pendidikan Nasional. (2005). Undang-Undang Republik Indonesia, Nomor 14 Tahun 2005 Tentang Guru dan Dosen. Depdiknas RI. https://jdih.kemenkeu.go.id/fulltext/2005/14tahun2005uu.htm

Elisa, \& Intan, N. (2019). Cerdas Menulis Buku Referensi. Deepublish Publisher.

Ermi, N. (2015). Penggunaan Metode Diskusi untuk Meningkatkan Hasil Belajar Materi Perubahan Sosial pada Siswa Kelas XII SMA Negeri 4 Pekanbaru. SOROT, 10(2), 155-168. https://doi.org/10.31258/sorot.10.2.155-168

Haerazi, H., Irawan, L. A., Rahman, A., Jupri, J., \& Warta, I. K. (2020). Publikasi IImiah untuk Akselerasi Kenaikan Pangkat Guru Bahasa Inggris SMP Negeri Se-Lombok Tengah. Sasambo: Jurnal Abdimas (Journal of Community Service), 2(1), 33. https://doi.org/10.36312/sasambo.v2i1.191

Millah, E. S., Budipramana, L. S., \& Isnawati. (2012). Pengembangan Buku Ajar Materi bioteknologi di Kelas XII SMA Ipiems Surabaya Berorientasi Sains, Teknologi, Lingkungan, dan Masyarakat (SETS). BioEdu, 1(1), Article 1. https://jurnalmahasiswa.unesa.ac.id/index.php/bioedu/article/view/344

Ristekdikti. (2019). Pedoman Operasional Penilaian Angka Kredit Kenaikan Jabatan Akademik/Pangkat Dosen. Direktorat Jenderal Sumber Daya Iptek Dan Dikti.

Rizka, M. A., Primawati, S. N., \& Mursali, S. (2016). IbM Pelatihan Pembuatan "Kerja Mas" (Keripik Jagung Manis) Berbasis Agropreneur. Jurnal Kependidikan: Jurnal Hasil Penelitian Dan Kajian Kepustakaan Di Bidang Pendidikan, Pengajaran Dan Pembelajaran, 2(2). https://doi.org/10.33394/jk.v2i2.456

Samani, M. \& Hariyanto. (2013). Pendidikan karakter konsep dan model. PT Remaja Rosdakarya.

Sopiah, S., Murdiono, A., Martha, J. A., Prabowo, S. H., \& Fitriana, F. (2019). Pelatihan dan Pendampingan Penyusunan Bahan Ajar Bagi Guru SMA 5 Kediri. Jurnal KARINOV, 2(1), 52-56. https://doi.org/10.17977/um045v2i1p52-56

WhatsApp. (2020). In Wikipedia bahasa Indonesia, ensiklopedia bebas. https://id. wikipedia.org/w/index.php?title=WhatsApp\&oldid=18201496 